\title{
Development of ocular hypertension and persistent glaucoma after intravitreal injection of triamcinolone
}

\section{Selim Kocabora \\ Cemil Yilmazli \\ Muhittin Taskapili \\ Gokhan Gulkilik \\ Sahan Durmaz}

Vakif Gureba Education and Research Hospital, Istanbul, Turkey
Correspondence: M Selim Kocabora Vatan caddesi,Vakif Gureba Egitim ve Arastirma Hastanesi, Fatih, 34 000, Istanbul, Turkey

Tel +902I2 5346900

Email kocabora@gmail.com
Purpose: This study evaluates intraocular pressure (IOP) elevation secondary to intravitreal injection of triamcinolone acetonide (IVTA) and discusses its management.

Methods: The records of 175 patients who underwent IVTA treatment and regular eye examinations in the period 2003-2006 were reviewed. One hundred and twenty-two of these patients were included in the study, of which 147 eyes that received IVTA $(4 \mathrm{mg} / 0.1 \mathrm{ml})$ were followed for at least 9 months. Mean IOPs observed after IVTA injection as well as IOP elevations defined as moderate ( $\geq 5 \mathrm{~mm} \mathrm{Hg}$ ), important $(\geq 10 \mathrm{~mm} \mathrm{Hg}$ ) and severe $(>25 \mathrm{~mm} \mathrm{Hg})$ during the follow-up period were evaluated and compared statistically.

Results: Overall, the mean IOPs following IVTA injection were statistically significantly higher than the preinjection IOP $(15.8 \pm 2.6)$, after the first hour $(17.7 \pm 2.9)$, the first week (18.7 \pm 4.1$)$, the first month (19.6 \pm 6.2$)$, the second month $(19.1 \pm 6.1)$, the third month $(18.0 \pm$ $4.1)$, the sixth month $(17.3 \pm 4.0)$, and the ninth month $(17.0 \pm 2.7)$, but not after the first day $(16.3 \pm 7.6)$. Important IOP elevations were observed mostly in the first $(17.7 \%)$ and second months (10.2\%). In 40 (27.7\%) eyes, topical antiglaucomatous therapy was needed and 7 later required surgical intervention to lower the IOP. Of the remaining 33 eyes, topical treatment was continued in $14(9.5 \%)$ because of IOPs $\geq 20 \mathrm{~mm} \mathrm{Hg}$.

Conclusion: The persistence of IOP elevation beyond the IVTA clearance period and the development of intractable secondary glaucoma requiring surgical intervention substantiate the need for careful consideration of IVTA indication and follow-up.

Keywords: intravitreal triamcinolone, intraocular pressure, steroid-induced glaucoma

\section{Introduction}

Over the past 5 years, intravitreal triamcinolone acetonide (IVTA) injection has emerged as an important and effective treatment modality for various intraocular pathologies (Jonas 2005; Jonas et al 2005). However, because the most common side effect of IVTA treatment is elevation of the intraocular pressure (IOP), the incidence of steroid-induced glaucoma has also increased.

Steroid-induced glaucoma has been well recognized since the independent studies of Armaly and Becker in the 1960s (Skuta 1996; Jones 2006). Corticosteroids are known to elevate the IOP by all routes of administration, but topical use of potent steroids causes IOP elevation in one-third of all eyes treated (Skuta 1996). The steroids indirectly cause a rise in IOP by promoting excessive deposition of extracellular material in the trabecular meshwork (TM), thus reducing the outflow of aqueous humor (Skuta 1996; Jones 2006). Armaly reported that 5\% of adult patients were high-responders (increases in IOP $>15 \mathrm{~mm} \mathrm{Hg}$ ), and as many as 3\% of steroid responders may experience persistent and irreversible IOP elevation (Skuta 1996; Jones 2006).

The pressure increases induced by IVTA tend to be more acute and significant than those caused by other modes of administration. However, a recent report showed that 
the ultrastuctural changes in the TM after IVTA treatment are similar to those resulting from hypertension after topical corticosteroid treatment (Kubota 2006). Rare causes of IOP elevation related to IVTA injection have included an early and rapid rise in IOP related to mechanical obstruction of the trabeculum by triamcinolone particles in pseudophakic eyes, and cases of angle closure and malignant glaucoma (Jonas et al 2003; Singh et al 2004; Sivaprasad et al 2006).

The serious rise in IOP due to IVTA can usually be managed successfully with topical medications. However, in a small percentage of eyes the hypertension may be uncontrollable with topical treatment; in such cases, surgical procedures to reduce the IOP should be carried out (Jonas 2005; Jonas et al 2005).

In this prospective study of patients treated with IVTA injections, we report our findings on the elevated IOP levels and the development of secondary chronic open angle glaucoma. We also discuss the treatment strategies and options we used in the management of these cases.

\section{Materials and methods}

The records of 175 patients who underwent IVTA treatment in the period 2003-2006 were reviewed. Fifty-three of these patients failed their regular eye examinations and were excluded from the study.

Eyes with known primary or secondary glaucoma were not taken into the study. Gonioscopic examination was done regularly in all patients before and after the IVTA injection. Patients with narrow or closed angles were not injected with IVTA, and during the follow-up we observed neither angle closure nor angle neovascularization development in any eye.

The IVTA injections were carried out by two vitreoretinal surgeons (M.S.K. and G.G.) under aseptic conditions. After topical anesthesia and asepsia by povidone-iodine, $4 \mathrm{mg} / 0.1 \mathrm{~mL}$ of triamcinolone was injected with a 27 gauge needle 3.5 to $4 \mathrm{~mm}$ from the limbus inferotemporally.

Regular eye examinations were done during the first hour and the first day, and then one week, one month, two months, three months, six months, and nine months after the injection. The IOP measurements were done routinely using a Goldmann applanation tonometer, but in rare instances a Tono-pen tonometer was also used.

After the first observation of IOP elevation, if the pressure remained above $25 \mathrm{~mm} \mathrm{Hg}$ at any follow-up examination, a topical medication to lower the IOP was considered. Dorzolamide, brinzolamide, and the combination of dorzolamide-timolol were the first choices for the topical treatment, but brimonidine was added when it was needed.
The preoperative IOP was statistically compared with the postinjection IOPs at different time points. The evaluation was made according to the magnitude of the IOP elevation and the rate at which the IOP dropped to below $21 \mathrm{~mm} \mathrm{Hg}$ in eyes treated with topical medications. Moderate and important IOP elevations above the preoperative baseline were defined as $\geq 5 \mathrm{~mm} \mathrm{Hg}$ and $\geq 10 \mathrm{~mm} \mathrm{Hg}$, respectively, based on previous studies. The need and the type of surgery performed to lower the IOP in the intractable cases $(>25 \mathrm{~mm} \mathrm{Hg}$ ) were noted. The type of surgery undertaken was decided based on the severity of the IOP elevation and the comorbidity of the eye.

Statistical analyses were done using SPSS software. Paired t test was used to compare the mean IOP values at different time intervals. A $p$ value of $\leq 0.05$ was considered statistically significant.

\section{Results}

One hundred and forty-seven eyes of 122 patients, 72 women and 50 men, which could be followed regularly for at least 9 months, were included in the study. The mean age of the patients was $58.4 \pm 9.1$ years (range 36-78). Patients with previous glaucoma did not receive IVTA treatment. The main indication for IVTA was macular edema caused by diabetic retinopathy in 121 eyes, retinal venous occlusion in 22 eyes, uveitis in 2 eyes, and subretinal choroidal neovascularization in 2 eyes. Twentyone eyes without a previous important increase in IOP received a second IVTA injection for persistent or recurrent diabetic macular edema without any subsequent IOP increase.

Besides the IOP elevation, other complications we observed following IVTA injection were secondary cataract development in 14 eyes, pseudohypopyon in 3 eyes, and bacterial endophthalmitis in 1 eye.

The mean IOPs and the IOP elevations at different followup intervals are shown in Table 1 and Table 2. All the eyes including those under topical treatment are included in the analyses.

In 40 eyes $(27.2 \%)$, topical treatment was initiated to reduce the IOP when persistent elevation above $25 \mathrm{~mm} \mathrm{Hg}$ was observed over one month in weekly examinations after the first observation of IOP $\geq 25 \mathrm{~mm} \mathrm{Hg}$. Subsequent surgical treatment was needed in 7 of the $40(4.7 \%)$ to reduce high IOP levels that were refractory to maximal medical therapy with 2 or 3 antiglaucomatous drugs. In the remaining 33 eyes, topical treatments were stopped in $19(13 \%)$ and continued in $14(9.5 \%)$ for at least nine months postinjection. Topical treatments were discontinued depending on the IOP level; an IOP $>20 \mathrm{~mm} \mathrm{Hg}$ despite treatment was considered an indication for continuing treatment. 
Table I Mean IOP values at different follow-up times

\begin{tabular}{lllllllll}
\hline Pre-IVTA & I hour & I day & I week & I month & 2 month & 3 month & 6 month & 9 month \\
\hline $15.8 \pm 2.62$ & $17.68 \pm 2.92$ & $I 6.26 \pm 7.56$ & $18.68 \pm 4.06$ & $19.6 \pm 6.22$ & $19.07 \pm 6.12$ & $18.02 \pm 4.12$ & $17.33 \pm 4.02$ & $16.96 \pm 2.67$ \\
& $\leq 0.000 \mathrm{I}$ & $=0.1426$ & $\leq 0.000 \mathrm{I}$ & $\leq 0.000 \mathrm{I}$ & $\leq 0.000 \mathrm{I}$ & $\leq 0.000 \mathrm{I}$ & $=0.000 \mathrm{I}$ & $=0.0002$ \\
\hline
\end{tabular}

Abbreviations: IOP, intraocular pressure; IVTA, intravitreal injection of triamcinolone acetonide.

Surgery for lowering the IOP was required for 7 (4.7\%) of the 147 eyes. The operations performed were trabeculectomy in 3, pars plana vitrectomy in 2, and cyclophotocoagulation in 2 eyes. All 7 eyes had an IOP $>32 \mathrm{~mm} \mathrm{Hg}$ despite medical treatment. In one eye, cyclophotocoagulation was repeated 1 month after the first procedure because of an inadequate reduction in IOP. In all 7 eyes the IOP returned to below $21 \mathrm{~mm} \mathrm{Hg}$ during the follow-up period after surgery.

When we compared the levels of IOP increases between the subgroups, we found that in the retinal venous occlusion cases (22 eyes) the IOP elevation was more pronounced compared with that of the diabetic retinopathy eyes, from the first month until the sixth month. Repeated IVTA injections in 21 eyes did not result in an increase in IOP.

\section{Discussion}

Intravitreal injection of long-acting steroids is indicated for the treatment of edematous, inflammatory, and neovascular intraocular diseases. The prolonged effect of triamcinolone is mainly due to its low water-solubility. Accordingly, measurable concentrations of triamcinolone can persist for at least 3 or 18 months after intravitreal injection of $4 \mathrm{mg}$ or 20-25 mg, respectively (Beer et al 2003; Heatley et al 2006). Triamcinolone was detected 2.75 to 5 months after intravitreal injection of $4 \mathrm{mg}$ (Mason et al 2004).

In our series, following IVTA injection, statistically significant increases in IOP levels were observed from the first week until the ninth month postinjection. Important IOP increases were first observed in the first week postinjection and then most frequently in the first month; thereafter the levels gradually declined due to the effect of the topical treatments and also probably to the clearance of triamcinolone from the vitreous cavity with time. The mean postinjection IOP measurements showed highly statistically significant differences $(\mathrm{p}<0.0001)$ at all time points, except in first day, compared with the baseline IOP. Surprisingly, the IOP levels during the first week after the injection were statistically significantly higher than the preinjection IOP, but only $2.7 \%$ of the eyes showed important IOP elevations.

In other studies, approximately a third to a half of all patients receiving IVTA treatment experienced an increase in IOP to above $21 \mathrm{~mm} \mathrm{Hg}$ (Wingate 1999; Bakri et al 2003; Smithen et al 2004; Jonas et al 2006; Kocabora et al 2007).

This prevalence may depend on several factors, including how the increase is defined, the dosage of IVTA, the baseline IOP, the age of the patient, and the type of concurrent eye disease. The high dosage used by Jonas (2005) was associated with a higher rate of IOP increase lasting up to 9 months longer than observed for the $4 \mathrm{mg}$ dose. A recent study reported that increases in IOP levels were mostly seen in relatively young patients with uveitis who had received a high dose of IVTA (Jonas 2007).

The standard dose of IVTA we used was $4 \mathrm{mg}$ in $0.1 \mathrm{ml}$. The significant increase in IOP levels observed in the first hour in our cases was probably due to the volume-effect of the injected IVTA; only $8.8 \%$ of the eyes showed a moderately elevated IOP in the first hour postinjection.

Gillies and colleagues (2006) reported an incidence of IOP elevation (increased by $>5 \mathrm{~mm} \mathrm{Hg}$ ) of $68 \%$, significantly higher than observed in previous studies, and rates of topical treatment and glaucoma surgery of $44 \%$ and $6 \%$, respectively.

In our series, the rates of topical treatment and surgery for reducing high IOP were $27 \%$ and $4.7 \%$, respectively. Considering the high concentration of intraocular triamcinolone and predisposing factors such as diabetes and arterial hypertension (Becker et al 1966; Langman et al 2005), these important rates were not surprising. The earliest topical

Table 2 Magnitudes of IOP increases at different follow-up times

\begin{tabular}{|c|c|c|c|c|c|c|c|c|c|}
\hline IOP increase & Pre-IVTA & I hour & I day & I week & I month & 2 month & 3 month & 6 month & 9 month \\
\hline$\geq 5 \mathrm{~mm} \mathrm{Hg}$ & - & I 3 (8.8\%) & 7 (4.7\%) & 35 (23.8\%) & $22(15 \%)$ & 15 (I0.2\%) & 22 (I5\%) & $2 \mathrm{I}(14.2 \%)$ & $2 \mathrm{I}(14.2 \%)$ \\
\hline$\geq 10 \mathrm{~mm} \mathrm{Hg}$ & - & $0(0 \%)$ & $0(0 \%)$ & $4(2.7 \%)$ & $26(17.7 \%)$ & 15 (10.2\%) & $8(5.4 \%)$ & $7(4.7 \%)$ & $3(2 \%)$ \\
\hline $\mathrm{IOP} \geq 25 \mathrm{~mm} \mathrm{Hg}$ & - & $0(0 \%)$ & $0(0 \%)$ & 14 (9.5\%) & $28(19 \%)$ & $18(12.2 \%)$ & $6(4.1 \%)$ & $5(3.4 \%)$ & $3(2 \%)$ \\
\hline
\end{tabular}

Abbreviations: IOP, intraocular pressure; IVTA, intravitreal injection of triamcinolone acetonide. 
treatment was started after the first month and the earliest surgery was performed after the second month.

The persistence of IOP elevation despite cessation of steroid treatment has been known for a long time (Spaeth et al 1977). The work of Armaly and Becker suggests that 5\%-6\% of the population will likely be high responders who develop important IOP elevations early after steroid use, apart from diabetic patients who are also known to be predisposed to IOP rises after steroid treatment (Skuta 1996). In our study, despite topical treatment, a surprisingly high IOP persisted in $9.5 \%$ of the eyes beyond 9 months; we considered these cases as secondary open angle glaucoma development due to IVTA. Unless most of our patients were diabetic, this rate is very high.

Severe and intractable IOP elevations, despite maximally tolerated medical therapy after IVTA, were reported to occur in some eyes, especially those with retinal vein occlusions (Kaushik et al 2004; Yang et al 2005; Quiram et al 2006). The reported treatment methods for secondary ocular hypertension after IVTA were argon laser trabeculoplasty, selective laser trabeculoplasty, trabeculectomy, drainage devices, and pars plana vitrectomy (Agrawal et al 2004; Kaushik et al 2004; Yang et al 2005; Pizzimenti et al 2006; Quiram et al 2006; Sivaprasad et al 2006; Viola et al 2006).

In our series of eyes, intractable glaucoma needing surgical intervention was observed in 7 eyes. The primary pathology was retinal venous occlusions in 2 of these eyes and diabetic retinopathy in 5 . We carried out trabeculectomies in 3 eyes and pars plana vitrectomies in 2 eyes all with severe IOP increases $>40 \mathrm{~mm} \mathrm{Hg}$ after the first month. Cyclophotocoagulations were performed in 2 eyes with relatively less severe IOP increases up to $32-35 \mathrm{~mm} \mathrm{Hg}$.

The persistence of IOP above $35 \mathrm{~mm} \mathrm{Hg}$ for days and weeks increases the risk of damage to the optic disc as well as retinal vascular occlusion. Therefore, it is absolutely necessary to perform a surgical procedure to lower the IOP to normal levels.

The choice of surgical modality should be made according to the magnitude of the IOP and the surgeon's experience. Trabeculectomy can be the first choice for the management of intractable ocular hypertension. Pars plana vitrectomy aims to decrease the IOP by removing intravitreal triamcinolone crystals, but it is a very aggressive way to reduce the IOP; therefore, the method should be limited to eyes that would receive additional benefit from this surgery. Cyclophotocoagulation is another technique we used to reduce the IOP because it is easy to perform and has fewer complications than the aforementioned surgeries.
Two potential drugs, anecortave and mifepristone, for the treatment of steroid-induced glaucoma (Green et al 1989; Robin et al 2005) might obviate the need for surgical treatment of triamcinolone-induced glaucoma.

The risk of secondary glaucoma needing permanent antiglaucomatous drug use and of a serious intractable IOP elevation requiring surgical intervention validate the necessity of a careful period of IVTA indication and follow up.

\section{References}

Agrawal S, Agrawal J, Agrawal TP. 2004. Vitrectomy as a treatment for elevated intraocular pressure following intravitreal injection of triamcinolone acetonide. Am J Ophthalmol, 138:679-80.

Bakri S, Beer PM. 2003. The effect of intravitreal triamcinolone acetonide on intraocular pressure. Ophthalmic Surg Lasers Imaging, 34:386-90.

Becker B, Bresnick G, Chevrette L, et al. 1966. Intraocular pressure and its response to topical corticosteroids in diabetes. Arch Ophthalmol, $76: 477-83$.

Beer PM, Bakri SJ, Singh RJ, et al. 2003. Intraocular concentration and pharmacokinetics of triamcinolone acetonide after a single intravitreal injection. Ophthalmology, 110:681-6.

Gillies MC, Sutter FK, Simpson JM, et al. 2006. Intravitreal triamcinolone for refractory diabetic macular edema: two-year results of a doublemasked, placebo-controlled, randomized clinical trial. Ophthalmology, 113:1533-8.

Green K, Cheeks L, Slagle T, et al. 1989. Interaction between progesterone and mifepristone on intraocular pressure in rabbits. Curr Eye Res, $8: 317-20$

Heatley CJ, Lim KS, Siriwardena D, et al. 2006. Malignant glaucoma as a complication of intravitreal triamcinolone acetonide. Acta Ophthalmol Scand, 84:712-13.

Jonas JB. 2004. Intraocular availability of triamcinolone acetonide after intravitreal injection. Am J Ophthalmol, 137:560-2.

Jonas JB. 2005. Intravitreal triamcinolone acetonide for treatment of intraocular oedematous and neovascular diseases. Acta Ophthalmol Scand, 83:645-63.

Jonas JB, Kreissig I, Degengring R. 2005. Intravitreal triamcinolone acetonide for treatment of intraocular proliferative, exudative and neovascular diseases. Prog Retin Eye Res, 24:587-611.

Jonas JB, Schlichtenbrede F. 2007. Visual acuity and intraocular pressure after high-dose intravitreal triamcinolone acetonide in selected ocular diseases. Eye, Feb 16; Epub ahead of print.

Jonas JB, Vossmerbaeumer U, Kamppeter BA. 2004. Chronic prephthisical ocular hypotony treated by intravitreal triamcinolone acetonide. Acta Ophthalmol Scand, 82:637.

Jonas JB, Kreissig I, Degengring R. 2003. Secondary chronic open-angle glaucoma after intravitreal triamcinolone acetonide. Arch Ophthalmol, 121:729-30.

Jonas JB, Spandau UH, Kamppeter U, et al. 2006. Follow-up after intravitreal triamcinolone acetonide for diabetic macular edema. Eur J Ophthalmol, 16:566-72.

Jones R, Rhee DJ. 2006. Corticosteroid-induced ocular hypertension and glaucoma: a brief review and update of the literature. Curr Opin Ophthalmol, 17:163-7.

Kaushik S, Gupta V, Gupta A, et al. 2004. Intractable glaucoma following triamcinolone in central retinal vein occlusion. Am J Opthalmol, 137:758-60.

Kocabora MS, Kucuksahin H, Gulkilik G, et al. 2007. Traitement de l'œdème maculaire diabétique par injection intravitréenne d'acétonide de triamcinolone: consequences fonctionelles et anatomiques. J Fr Ophthalmol, 30:32-8. 
Kubota T, Okabe H, Hisatomi T, et al. 2006. Ultrastructure of the trabecular meshwork in secondary glaucoma eyes after intravitreal triamcinolone acetonide. J Glaucoma, 15:117-19.

Langman MJ, Lancashire RJ, Cheng KK, et al. 2005. Systemic hypertension and glaucoma: mechanisms in common and co-occurrence. Br J Ophthalmol, 89:960-3.

Mason JO 3rd, Somaiya MD, Singh RJ. 2004. Intravitreal concentration and clearance of triamcinolone acetonide in nonvitrectomized human eyes. Retina, 24:900-4.

Park HY, Yi K, Kim HK. 2005. Intraocular pressure elevation after intravitreal triamcinolone acetonide injection. Korean J Ophthalmol, 19:122-7.

Pizzimenti JJ, Nickerson MM, Pizzimenti CE, et al. 2006. Selective laser trabeculoplasty for intraocular pressure elevation after intravitreal triamcinolone acetonide injection. Optom Vis Sci, 83:421-5.

Robin A, Sjaarda R, Suan EP. 2005. Sub-Tenon's anecortave acetate lowers intraocular pressure elevation caused by intravitreal triamcinolone: a novel therapy [poster]. Presented at: American Academy of Ophthalmology meeting, October, 2005; Chicago, Illinois.

Quiram PA, Gonzales CR, Schwartz SD. 2006. Severe steroid-induced glaucoma following intravitreal injection of triamcinolone acetonide. Am J Ophthalmol, 141:580-2.
Singh IP, Ahmad SI, Yeh D, et al. 2004. Early rapid rise in intraocular pressure after intravitreal triamcinolone acetonide injection. $\mathrm{Am} \mathrm{J}$ Ophthalmol, 138:286-7.

Sivaprasad S, McCluskey P, Lightman S. 2006. Intravitreal steroids in the management of macular oedema. Acta Ophthalmol Scand, 84:722-33.

Skuta GL, Morgan RK. 1996. Corticosteroid-induced glaucoma. In: Ritch R, Shields MB, Krupin T eds. The Glaucomas, Vol II. 2nd ed. St Louis: Mosby, pp 1177-88.

Smithen LM, Ober MD, Maranan L, et al. 2004. Intravitreal triamcinolone acetonide and intraocular pressure. Am J Ophthalmol, 38:740-3.

Spaeth GL, Rodrigues MM, Weinreb S. 1977. Steroid-induced glaucoma: A. Persistent elevation of intraocular pressure. B. Histopathological aspects. Trans Am Ophthalmol Soc, 75:353-81.

Viola F, Morescalchi F, Staurenghi G. 2006. Argon laser trabeculoplasty for intractable glaucoma following triamcinolone. Arch Ophthalmol, 124:133-4.

Wingate RJ, Beaumont PE. 1999. Intravitreal triamcinolone and elevated intraocular pressure. Aust N Z J Ophthalmol, 27:431-2.

Yang CS, Chen MJ, Chou CK, et al. 2005. Refractory severe ocular hypertension after intravitreal triamcinolone injection. Ophthalmologica, 219:413-5. 
